IZA DP No. 5679

Is Earnings Uncertainty Relevant for Educational Choice? An Empirical Analysis for China

Joop Hartog

Xiaohao Ding

Juan Liao

April 2011 


\title{
Is Earnings Uncertainty Relevant for Educational Choice? An Empirical Analysis for China
}

\author{
Joop Hartog \\ University of Amsterdam \\ and IZA \\ Xiaohao Ding \\ Peking University \\ Juan Liao \\ Peking University
}

\author{
Discussion Paper No. 5679 \\ April 2011 \\ IZA \\ P.O. Box 7240 \\ 53072 Bonn \\ Germany \\ Phone: +49-228-3894-0 \\ Fax: +49-228-3894-180 \\ E-mail: iza@iza.org
}

Any opinions expressed here are those of the author(s) and not those of IZA. Research published in this series may include views on policy, but the institute itself takes no institutional policy positions.

The Institute for the Study of Labor (IZA) in Bonn is a local and virtual international research center and a place of communication between science, politics and business. IZA is an independent nonprofit organization supported by Deutsche Post Foundation. The center is associated with the University of Bonn and offers a stimulating research environment through its international network, workshops and conferences, data service, project support, research visits and doctoral program. IZA engages in (i) original and internationally competitive research in all fields of labor economics, (ii) development of policy concepts, and (iii) dissemination of research results and concepts to the interested public.

IZA Discussion Papers often represent preliminary work and are circulated to encourage discussion. Citation of such a paper should account for its provisional character. A revised version may be available directly from the author. 
IZA Discussion Paper No. 5679

April 2011

\section{ABSTRACT \\ Is Earnings Uncertainty Relevant for Educational Choice? An Empirical Analysis for China}

We use the method of Dominitz and Manski (1996) to solicit anticipated wage distributions for continuing to a Master degree or going to work after completing the Bachelor degree. The means of the distributions have an effect on intention to continue as predicted by theory. The dispersions in these individual distributions have no effect on intention to continue, suggesting that anticipated earnings risk does not play a role in the decision.

JEL Classification: D8, I21, J24

Keywords: wage expectations, educational choice

Corresponding author:

Joop Hartog

University of Amsterdam

Roetersstraat 11

1018 WB Amsterdam

The Netherlands

E-mail: j.hartog@uva.nl 


\section{Introduction}

In a survey among university undergraduates in Beijing, we have asked earnings expectations for two scenarios: go to work after completing their Bachelor degree or finish a Master degree and then go to work. Applying the method developed by Dominitz and Manski (1996), asking for the probabilities that income will be $25 \%$ above or below the expected value, we have an indication of the extent of uncertainty or risk implicit in their anticipated earnings. We relate the intention to continue education for a Master degree to expected earnings and to anticipated uncertainty and find that the former has significant effect and the latter has not.

Our results contribute to a very small literature ${ }^{1}$. After the seminal contribution by Levhari and Weiss (1974), there was related work by Eaton and Rosen (1980) and Kodde (1985). Williams (1979) moves away from single up front decision making by applying stochastic dynamic programming. Belzil and Hansen (2002) estimate such a model on American data. Groot and Oosterbeek (1992) extend the basic human capital model with unemployment risk and a wage offer distribution rather than a single given wage. The special issue on Education and Risk published by Labour Economics in 2007 testifies of a growing interest in the topic. Still, many questions are waiting for an answer.

The contribution of this paper is the combination of privately held perceptions on the wage consequences of different schooling scenarios with intended choice for one of these scenarios. This, in our view, has decisive methodological virtue. With our data, there is no need to worry about selectivity in observed wage data, as individuals reveal their private information in the anticipated wage distributions that they provide. A potential drawback is that we use intentions rather than actual outcomes. The effect may be minor in our case, where the time interval between measured intention and actual choice is small. Still, an obvious extension of our work will be to collect to collect data on perceived effects of schooling alternatives and actual choices.

\footnotetext{
${ }^{1}$ A more extensive review of literature is given in Hartog and Bajdechi (2007).
} 


\section{The survey}

In June 2007, we held a survey among bachelor students of six universities in Beijing. We gave out the questionnaires to the Students Affairs Department of the six universities, and let the staff of the department take care of the distribution. We asked them to give out the questionnaires to junior and senior students. At the same time, they should consider major/gender/family background when the respondents were selected. We have no reason to suspect systematic deviation from randomness and certainly not selectivity in relation to anticipated questionnaire answers. 4600 questionnaires were sent out and 4272 valid questionnaires were retrieved, a response rate of 93\%. In the survey we asked for personal (demographic) information, family background, plans and ambitions and risk attitudes. We also asked the following question:

We now ask you about your expectation of future earnings. Suppose you find a job after graduation as a bachelor student :

(1) the earnings you expect for your first job:_Yuan/month

(2) the probability of earning less than $75 \%$ of stated expected wages, rounded at nearest 10 Yuan

(3) the probability of earning more than $125 \%$ of stated expected wages, rounded at nearest 10 Yuan

We asked the same earnings questions with ten years of work experience. We also asked all these questions after completing a Master: Now suppose you continue education after you graduate as a master student. If you go to work, etc.

We also ask for plans after graduation as a bachelor. Among our 4272 respondents, 2913 or 68 percent intend to continue their studies while the remaining 1359 or 32 percent plan to start working. The dependent variable in our analysis will be the plan after obtaining the bachelor degree: continue education or work. 
In Table 1 we characterise our sample: the variables we use as controls and their means and standard deviations. Bachelor students who plan to work after graduation, rather than continue for a Master degree, come from families with slightly higher average income, lower levels of parental education and occupation and come less often from a large city. Students in engineering, science and management dominate in our data. All students overrate their academic performance, illustrating a well known phenomenon; but those who plan for work rate themselves lower in academic performance that those who plan for continued education.

\section{The quality of the earnings anticipations}

Earlier work has shown that the Dominitz-Manski method generates data of good quality (Dominitz and Manski, 1996; Manski, 2004; Schweri, Hartog and Wolter, 2011; Wolter, 2000; Attanasio and Kaufmann, 2010). If respondents are not constrained to obey the rules of probability, they may give inconsistent answers, but in the applications so far this appeared to be an insignificant problem, as could be checked by using recording of violations. In Table 2 we collect information on three types of inconsistencies: $\mathrm{P}(75)$, $\mathrm{P}(125)$ or $\mathrm{P}(75)+\mathrm{P}(125)$ greater than 100 , where $\mathrm{P}(75)$ stands for the probability of earnings below 75 percent of the expected value and $\mathrm{P}(125)$ for the probability of earnings above 125 percent of the expected value. We do this separately for Bachelor (B) and Master (M), at 0 and 10 years of experience. The scores are cumulative within each column. 784 individuals or 18 percent of the 4272 respondents violate the range restriction of probability at least once ${ }^{2}$. Hence, 82 percent did not violate a range restriction in a survey where we did not explain anything about the nature of probability. In Schweri, Hartog and Wolter (2011), 65 percent of the sample of Swiss students never violated the range restriction; however, neither omitting the small group of respondents who committed more than one violation or leaving inconsistent data in and identify such

\footnotetext{
${ }^{2}$ By imposing non-negativity on wages and applying minimum values for inequality restrictions (eg set wage equal to zero for the case of wages below 75 percent of the expectation), we can add further consistency tests by restricting the admitted range for expected wages. This generates no additional violations.
} 
data points with a dummy variable had any effect on the results of that paper. We will apply similar sensitivity checks to our estimates.

\section{The expectations}

Each individual provides us with four earnings expectations (conditional on Bachelor or Master diploma, with 0 and 10 years of experience, indicated as M0B, M10B, M0M and M10M, respectively) and eight probabilities (25\% below or above expected earnings, conditional on Bachelor or Master diploma, with 0 and 10 years of experience). We define earnings risk $\mathrm{R}$ as the probability of obtaining earnings below $75 \%$ or above $125 \%$ of the expected value, by simply adding up the two tail probabilities ${ }^{3}$. We will indicate the four risk measures, similar to expected earnings, as R0B, R10B, R0M and R10M. We will also define simple lifetime measures, by adding up values specified for zero experience and three times the values for 10 years experience, thus assuming a very simple lifetime profile. Discounting without any information on individual variation in discount rates makes no sense, as it would involve the same scaling factor for each individual. Lifetime values, for expected earnings and for probabilities (risk) will be indicated with L replacing 0 or 10.

Table 3 presents sample characteristics for the base sample and for what we call the regression sample. The base sample, containing all valid observations, has different number of observations for different variables because of item non-response. In the regression sample we have eliminated outliers. Among the 4272 valid observations, we first restrict the sample to questionnaires with all anticipated average earnings data complete $(\mathrm{N}=3616)$, then drop the top $1 \%$ and the bottom $1 \%$ of lifetime incomes $(\mathrm{N}=$ 3543) and finally restrict to questionnaires with all anticipated probabilities complete. The resulting sample of 3463 observations will be used for the regression analyses below (the "regression sample”). We also have a sample obtained after eliminating answers

\footnotetext{
${ }^{3}$ We might have multiplied the joint tail probability by expected earnings, to proxy a standard deviation measured in the money metric. Using only the tail probabilities has the advantage of keeping the measure of risk independent of expected earnings.
} 
inconsistent with probability theory, the "no-inconsistency" sample, with 2947 observations.

The means of expected earnings, are presented in Table 3. A surprisingly high mean for inexperienced Bachelors is redressed if the sample is trimmed to eliminate outliers. On average all individuals expect substantial earnings growth with experience. The increase in average expected earnings between Master and Bachelor is smaller for those who intend to continue for a Master than for those who do not intend so (marginally so with no experience, but substantially so at 10 years of experience). This seems at variance with positive self-selection, although we should note that we consider growth in the means, not mean growth rates. Lifetime expectations are reported as the ratio between Master and Bachelor lifetime income (MLMB) and between Master and Bachelor lifetime risk (RLMB). The mean lifetime advantage is slightly larger for those who intend to go for a Master degree than for those who intend to stop with a Bachelor. Risk on average is smaller for those who intend to continue than for those who intend to stop, but the differences are truly marginal and disappear in the lifetime aggregation.

The standard deviations of the distributions of lifetime ratios do not differ, but as Figure 1 shows, they hide differences in shape: those who intend to stop have a more spiky distribution. Item non-response is higher among those who intend to go to work than among those who intend to continue school: We know the ratio of lifetime incomes for $59 \%$ of the former and for $70 \%$ of the latter.

\section{Is uncertainty relevant? Baseline regressions}

Table 4 presents results of a logit regression on the intention to continue education at Master level. We have estimated six specifications:

1) all four income levels $\mathrm{M} 0 \mathrm{~B}, \mathrm{M} 10 \mathrm{~B}, \mathrm{M} 0 \mathrm{M}, \mathrm{M} 10 \mathrm{M}$ and all four probability levels R0B, R10B, R0M, R10M, 
2) all four income levels in logs and all four probability levels

3) the ratio's of income and probabilities for Master and Bachelor (eg M0M/M0B)

4) lifetime income with Bachelor and with Master and lifetime risk with Bachelor and Master (value at zero experience plus 3 times value at 10 years experience)

5) the log of lifetime income with Bachelor and log of lifetime income with Master and lifetime risk with Bachelor and Master

6) the ratio of lifetime income and lifetime risk

We only get statistically significant results with specifications 2 and 5 . The stronger performance of these logarithmic specifications neatly supports the human capital model. Results for the two specifications are reported in Table 4. The first two columns of the table give results when we use all observations, even if reported probabilities are inconsistent. We find that the logarithm of anticipated income with a Bachelor diploma has a negative effect on the inclination to continue education while anticipated income with a Master diploma has a positive effect, precisely as standard theory predicts. The four incomes have different weights in the decision. In specification (2), the income as experienced Bachelor has higher weight than the starting income, while the reverse holds for Master incomes. At zero experience, the Master income carries greater weight than the Bachelor income, but at 10 years experience, the Bachelor income dominates. In specification (5), with lifetime incomes, lifetime Master income dominates, although the weights are not far apart: if lifetime incomes as Bachelor and as Master increase at the same rate, the inclination to continue education increases.

Risk is never significant. Adding a dummy to identify cases with inconsistent probabilities has no effect on estimated coefficients and is statistically insignificant. The results are qualitatively not different when we exclude observations with inconsistent probabilities. In fact, by excluding the inconsistent records we gain precision in the key results.

Most controls have no significant effect: gender, degree of urbanisation of residence, field of study, family income and parental job type and education do not influence the 
intention for further studies. Age of the respondent has a negative effect. Academic performance (grade quartile) has a strong positive effect. These results are quite remarkable: intention to continue is only significantly affected by academic ability, family background is entirely irrelevant. The effects of self-assessed ability (grade) quartile are substantial: with the lowest quartile as reference, in specification (4) of Table 4, the marginal effects (and standard errors) are 0.074 (0.028), 0.162 (0.026) and 0.257 (0.022).

\section{Adding risk attitudes.}

We have asked for risk attitudes with the following question: A person can behave differently in different fields. How would you assess your willingness to take risk in the following fields? The fields are Finance, Leisure/sports, Health, Education and Career. A respondent can answer in 11 categories, from 0 , not at all prepared to take risk, to 10, very much prepared to take risk. This question has been used successfully elsewhere (Bonin et al). Empirical validation shows it correlates positively with risk attitudes derived from gambles with real money, but far from perfectly so (Dohmen et al; Hartog, Ding and Sun, 2010). We use the response in the field of education. The median value is between 5 and 6 (see Appendix A). If we were to consider a score of 5 as risk neutral, $44 \%$ of respondents would be risk neutral, $28 \%$ risk averse and also $28 \%$ would be risk loving. The distribution would not be symmetric though, but have negative skew.

Risk attitudes are supposed to have an impact through the response to perceived risk: risk averse individuals should respond more negatively to risk than risk lovers. We acknowledge this by specifying an interaction term for risk and risk attitude:

$\left(a R L B+\sum b_{i} D_{i} R L B\right)+\left(c R L M+\sum d_{i} D_{i} R L M\right)$ where dummy $D_{i}=1$ if risk attitude RA is in interval $\mathrm{i}$, and zero otherwise. Neither risk itself nor interaction with risk attitude has any significant effect. If we plot the coefficients, as in figure 2, the pattern does hint at systematic effects. The magnitude of the interaction effects decreases with declining risk aversion, and the signs of the coefficients tend to be opposite. Declining magnitudes are in conformity with theory: declining risk aversion should indeed lower the impact of risk. 
However, the signs are contrary to expectation: risk in Bachelor earnings should have a positive effect on inclination to continue education, risk in Master earnings a negative effect. Thus, we should conclude that in our data risk does not have the impact on educational choice as theory predicts.

\section{Conclusion}

Our conclusion on the key question is quite clear. Anticipated risk, measured as dispersion in the individually anticipated wage distributions for different schooling scenarios, has no effect on the intended schooling choices. Mean earnings, however, do have the effect that theory predicts. We cannot claim causality here, as we cannot rule out that schooling intentions have an impact on stated earnings expectations. Repeating the experiment in different settings is needed to check if our results have general validity. 


\section{References}

Attanasio, O. and K. Kaufman (2010), Educational choices and subjective expectations of returns: evidence on intra-household decisions and gender differences, paper presented at the 2010 CESifo Area Conference on Economics of Education, Munchen

Belzil, C. and J. Hansen (2002), Unobserved Ability and the Return to Schooling, Econometrica, 70(5), 2075-2091

Bonin, H., T. Dohmen, A. Falk, D. Huffman and U. Sunde (2007), Cross-sectional Earnings Risk and Occupational Sorting: The Role of Risk Attitudes, Labour Economics, 14(6), 926-937

Dohmen, T., A. Falk, D. Huffman en U. Sunde (2006), Individual risk attitudes: new evidence from a large representative experimentally validated survey. IZA Discussion Paper 1730

Dominitz, J. and C. Manski (1996), Eliciting student expectations of the return to schooling, Journal of Human Resources, 31, 1-26.

Eaton, J. and H. Rosen (1980), Taxation, Human Capital, and Uncertainty, American Economic Review, 70(4), 705-715,

Groot, W. and H. Oosterbeek (1992), Optimal investments in human capital under uncertainty, Economics of Education Review, 11 (1), 41-49.

Hartog, J. and S. Bajdech Human capital and risk, In: Human Capital, Advances in Theory and Evidence, Cambridge: Cambridge University Press, J. Hartog and H.

Maassen van den Brink, editors, 134-151

Hartog, J. , X. Ding and Y. Sun (2010), Can We Measure Individual Risk Attitudes in a Survey?, IZA Discussion Paper 4807

Kodde, D. (1985), Microeconomic analysis of demand for education, PhD thesis Erasmus University Rotterdam

Levhari, D. and Y. Weiss (1974), The effect of risk on the investment in human capital. American Economic Review, 64 (6), 950-963.

Manski, C.F. (2004), Measuring Expectations, Econometrica, 72 (5), 1329-1376 
Schweri, J., J. Hartog and S. Wolter (2011), Do students expect compensation for wage risk? Economics of Education Review, 30 (2), 215-227

Williams (1979) Williams, J. (1979), Uncertainty and the accumulation of human capital over the lifecycle, Journal of Business, 52, 521-548.

Wolter, S. (2000). Wage expectations: A comparison of Swiss and US Students, Kyklos $53,51-69$. 
Table 1. Sample characteristics (percentage distributions and income levels)

\begin{tabular}{|c|c|c|c|c|}
\hline & \multicolumn{2}{|c|}{ continue education } & \multicolumn{2}{|c|}{ going to work } \\
\hline \multicolumn{5}{|l|}{ Major } \\
\hline Philosophy & \multicolumn{2}{|l|}{0.77} & \multicolumn{2}{|l|}{0.30} \\
\hline Economics & \multicolumn{2}{|l|}{7.86} & \multicolumn{2}{|l|}{8.81} \\
\hline Law & \multicolumn{2}{|l|}{4.12} & \multicolumn{2}{|l|}{5.87} \\
\hline Educational studies & \multicolumn{2}{|l|}{0.28} & \multicolumn{2}{|l|}{0.23} \\
\hline $\begin{array}{l}\text { Chinese language } \\
\text { and literature }\end{array}$ & \multicolumn{2}{|l|}{5.94} & \multicolumn{2}{|l|}{7.76} \\
\hline History & \multicolumn{2}{|l|}{0.07} & \multicolumn{2}{|l|}{0.08} \\
\hline Science studies & \multicolumn{2}{|l|}{18.19} & \multicolumn{2}{|l|}{8.89} \\
\hline Engineering & \multicolumn{2}{|l|}{47.73} & \multicolumn{2}{|l|}{53.61} \\
\hline Agriculture & \multicolumn{2}{|l|}{0.07} & \multicolumn{2}{|l|}{0.00} \\
\hline Medical studies & \multicolumn{2}{|l|}{4.78} & \multicolumn{2}{|l|}{0.90} \\
\hline Management Science & \multicolumn{2}{|l|}{10.13} & \multicolumn{2}{|l|}{13.55} \\
\hline Strategics & \multicolumn{2}{|l|}{0.07} & \multicolumn{2}{|l|}{0.00} \\
\hline \multicolumn{5}{|l|}{ Academic performance } \\
\hline Lowest 25\% & \multicolumn{2}{|l|}{6.96} & \multicolumn{2}{|l|}{14.38} \\
\hline Lower 25\% & \multicolumn{2}{|l|}{23.55} & \multicolumn{2}{|l|}{34.46} \\
\hline Upper 25\% & 36.77 & & 35.38 & \\
\hline Тор 25\% & 32.72 & & 15.77 & \\
\hline Home location & & & & \\
\hline Village & 15.35 & & 22.08 & \\
\hline Town or township level & 7.54 & & 10.39 & \\
\hline County town & 31.33 & & 29.63 & \\
\hline City & 45.78 & & 37.91 & \\
\hline Female & 0.38 & & 0.36 & \\
\hline Parents' occupation & father & mother & father & mother \\
\hline Administrator & 15.44 & 5.12 & 10.57 & 3.23 \\
\hline Manager & 5.44 & 2.71 & 4.81 & 3.46 \\
\hline Clerical/office staff & 20.52 & 20.46 & 14.20 & 13.53 \\
\hline
\end{tabular}




\begin{tabular}{|c|c|c|c|c|}
\hline Professional & 8.89 & 9.56 & 7.02 & 5.11 \\
\hline Self-employed & 7.16 & 5.88 & 9.07 & 6.77 \\
\hline $\begin{array}{l}\text { Salesclerk or } \quad \text { Service } \\
\text { worker }\end{array}$ & 1.76 & 4.15 & 2.52 & 4.41 \\
\hline Owner of private firm & 4.14 & 2.38 & 5.21 & 3.46 \\
\hline Worker & 10.08 & 7.87 & 10.02 & 7.47 \\
\hline Farmer/herdsman/fisherfolk & 14.04 & 16.20 & 22.24 & 23.76 \\
\hline Retired staff & 3.96 & 9.64 & 4.73 & 11.33 \\
\hline $\begin{array}{l}\text { Unemployed,partly } \\
\text { unemployed }\end{array}$ & 3.42 & 10.43 & 4.34 & 11.49 \\
\hline Other & 5.15 & 5.59 & 5.28 & 5.98 \\
\hline \multicolumn{5}{|l|}{ Parents' education } \\
\hline Never schooled & 1.25 & 3.46 & 2.47 & 5.42 \\
\hline Elementary school & 4.95 & 9.90 & 8.42 & 13.94 \\
\hline Junior middle school & 16.50 & 17.31 & 22.02 & 23.39 \\
\hline Senior middle school & 27.01 & 29.14 & 32.30 & 29.12 \\
\hline $\begin{array}{l}\text { Professional middle school/ } \\
\text { Technical secondary school }\end{array}$ & 4.53 & 7.77 & 4.56 & 5.27 \\
\hline Junior college & 18.85 & 16.17 & 13.60 & 12.01 \\
\hline College/university & 21.92 & 14.07 & 14.22 & 9.14 \\
\hline \multirow[t]{2}{*}{ Graduate } & 4.99 & 2.17 & 2.40 & 1.70 \\
\hline & Mean & S.D & Mean & S.D \\
\hline Family Income (per year) & 38250 & 43438 & 33964 & 46906 \\
\hline Age & 21.31 & 0.98 & 21.60 & 1.08 \\
\hline $\mathrm{N}$ & 2,913 & & 1,359 & \\
\hline
\end{tabular}


Table 2. Inconsistency of earnings expectations

\begin{tabular}{|l|l|l|l|l|}
\hline & $(1)$ & $(2)$ & $(3)$ & \multicolumn{1}{|c|}{$(4)$} \\
\hline & $\begin{array}{l}\mathrm{P}(75) \\
100\end{array}$ & $\mathrm{P}(125)>100$ & $\begin{array}{l}\mathrm{P}(75)+ \\
\mathrm{P}(125) \\
>100\end{array}$ & $\begin{array}{l}\text { At least one } \\
\text { of these 3 } \\
\text { conditions }\end{array}$ \\
\hline M0B & 385 & 392 & 709 & 709 \\
\hline M10B & 434 & 436 & 754 & 754 \\
\hline M0M & 470 & 474 & 740 & 740 \\
\hline M10M & 512 & 517 & 784 & 784 \\
\hline
\end{tabular}


Table 3 Expected incomes and anticipated risk

\begin{tabular}{|c|c|c|c|c|c|c|c|c|c|}
\hline & \multicolumn{5}{|c|}{ all observations } & \multicolumn{4}{|c|}{ regression sample $\quad(\mathrm{N}=3466)$} \\
\hline & \multicolumn{2}{|l|}{ Stop } & \multicolumn{3}{|c|}{ Continue } & \multicolumn{2}{|c|}{ stop $(N=1030)$} & \multicolumn{2}{|c|}{ continue $(\mathrm{N}=2436)$} \\
\hline & mean & st dev & $\mathrm{N}$ & mean & st dev & mean & st dev & mean & st dev \\
\hline MOB & 130412173 & 279549 & 2683 & 4071 & 27488 & 2936 & 2601 & 3264 & 3391 \\
\hline M10B & 126438003 & 570065 & 2599 & 35682 & 487790 & 17458 & 65504 & 21722 & 216125 \\
\hline MOM & 11334808 & 6952 & 2741 & 6406 & 42940 & 4774 & 6597 & 5249 & 5100 \\
\hline M10M & 110731907 & 180052 & 2674 & 36500 & 303202 & 29529 & 180714 & 31597 & 241503 \\
\hline MLMB & 10521.52 & 1.09 & 2491 & 1.57 & 0.99 & 1.52 & 1.09 & 1.56 & 0.97 \\
\hline ROB & 127872.80 & 42.58 & 2605 & 71.06 & 45.22 & 73.06 & 38.11 & 70.78 & 36.20 \\
\hline R10B & 125775.51 & 34.97 & 2579 & 74.73 & 35.27 & 76.40 & 33.83 & 75.03 & 34.20 \\
\hline ROM & 111672.41 & 35.69 & 2683 & 70.76 & 35.08 & 72.48 & 35.07 & 70.71 & 34.05 \\
\hline R10M & 110474.01 & 35.29 & 2654 & 73.36 & 34.87 & 74.18 & 34.42 & 73.07 & 33.84 \\
\hline RLMB & 10301.03 & 0.57 & 2436 & 1.03 & 0.53 & 1.03 & 0.57 & 1.03 & 0.53 \\
\hline
\end{tabular}


Table 4 Logit estimates: intention to continue to Master education (coefficients x 100)

\begin{tabular}{|c|c|c|c|c|}
\hline \multirow{3}{*}{$\begin{array}{l}\text { specification } \\
\text { lgM0B }\end{array}$} & \multicolumn{2}{|c|}{$\begin{array}{c}\text { Inconsistent probabilities } \\
\text { included }\end{array}$} & \multicolumn{2}{|c|}{$\begin{array}{c}\text { Inconsistent probabilities } \\
\text { excluded }\end{array}$} \\
\hline & (2) & (5) & (2) & (5) \\
\hline & $\begin{array}{c}-0.123 \\
(11.490)\end{array}$ & & $\begin{array}{l}-7.225 \\
(13.365)\end{array}$ & \\
\hline $\operatorname{lgM} 10 \mathrm{~B}$ & $\begin{array}{c}-20.942^{* *} \\
(8.111)\end{array}$ & & $\begin{array}{l}-29.115^{* *} \\
(9.368)\end{array}$ & \\
\hline $\operatorname{lgM} 0 \mathrm{M}$ & $\begin{array}{l}48.343^{* * *} \\
(10.602)\end{array}$ & & $\begin{array}{l}59.289^{* * * *} \\
(12.257)\end{array}$ & \\
\hline $\operatorname{lgM} 10 \mathrm{M}$ & $\begin{array}{l}14.121^{*} \\
(6.967)\end{array}$ & & $\begin{array}{c}22.936^{* *} \\
(8.074)\end{array}$ & \\
\hline R0B & $\begin{array}{l}-0.171 \\
(0.161)\end{array}$ & & $\begin{array}{l}-0.265 \\
(0.252)\end{array}$ & \\
\hline R10B & $\begin{array}{c}0.080 \\
(0.201)\end{array}$ & & $\begin{array}{l}-0.154 \\
(0.274)\end{array}$ & \\
\hline R0M & $\begin{array}{l}-0.019 \\
(0.209)\end{array}$ & & $\begin{array}{c}0.083 \\
(0.286)\end{array}$ & \\
\hline R10M & $\begin{array}{c}0.124 \\
(0.216)\end{array}$ & & $\begin{array}{c}0.258 \\
(0.290)\end{array}$ & \\
\hline $\operatorname{lgMLB}$ & & $\begin{array}{c}-30.088^{* *} \\
(9.994)\end{array}$ & & $\begin{array}{c}-43.353^{* * *} \\
(11.433)\end{array}$ \\
\hline $\operatorname{lgMLM}$ & & $\begin{array}{c}38.141^{* * *} \\
(9.243)\end{array}$ & & $\begin{array}{l}52.086^{* * *} \\
(10.596)\end{array}$ \\
\hline RLB & & $\begin{array}{l}-0.027 \\
(0.055)\end{array}$ & & $\begin{array}{l}-0.104 \\
(0.075)\end{array}$ \\
\hline RLM & & $\begin{array}{c}0.018 \\
(0.054)\end{array}$ & & $\begin{array}{c}0.069 \\
(0.073)\end{array}$ \\
\hline cons & $\begin{array}{c}1.768 \\
(1.485)\end{array}$ & $\begin{array}{l}4.158^{* *} \\
(1.402)\end{array}$ & $\begin{array}{c}1.449 \\
(1.811)\end{array}$ & $\begin{array}{l}4.197^{*} \\
(1.709)\end{array}$ \\
\hline $\begin{array}{l}N \\
\text { pseudo } R^{2}\end{array}$ & $\begin{array}{l}3463 \\
0.107\end{array}$ & $\begin{array}{l}3463 \\
0.101\end{array}$ & $\begin{array}{l}2947 \\
0.115\end{array}$ & $\begin{array}{l}2947 \\
0.109\end{array}$ \\
\hline $\begin{array}{l}\text { Log } \\
\text { likelihood }\end{array}$ & -1881.923 & -1894.657 & -1571.900 & -1583.792 \\
\hline
\end{tabular}

Standard errors in parentheses

${ }^{*} p<0.05,{ }^{* *} p<0.01,{ }^{* * *} p<0.001$

All regressions include controls for age, gender, residence, field of study, grades and parental background 
Figure 1. Distribution of ratios of lifetime returns, Master over Bachelor degree; regression sample.
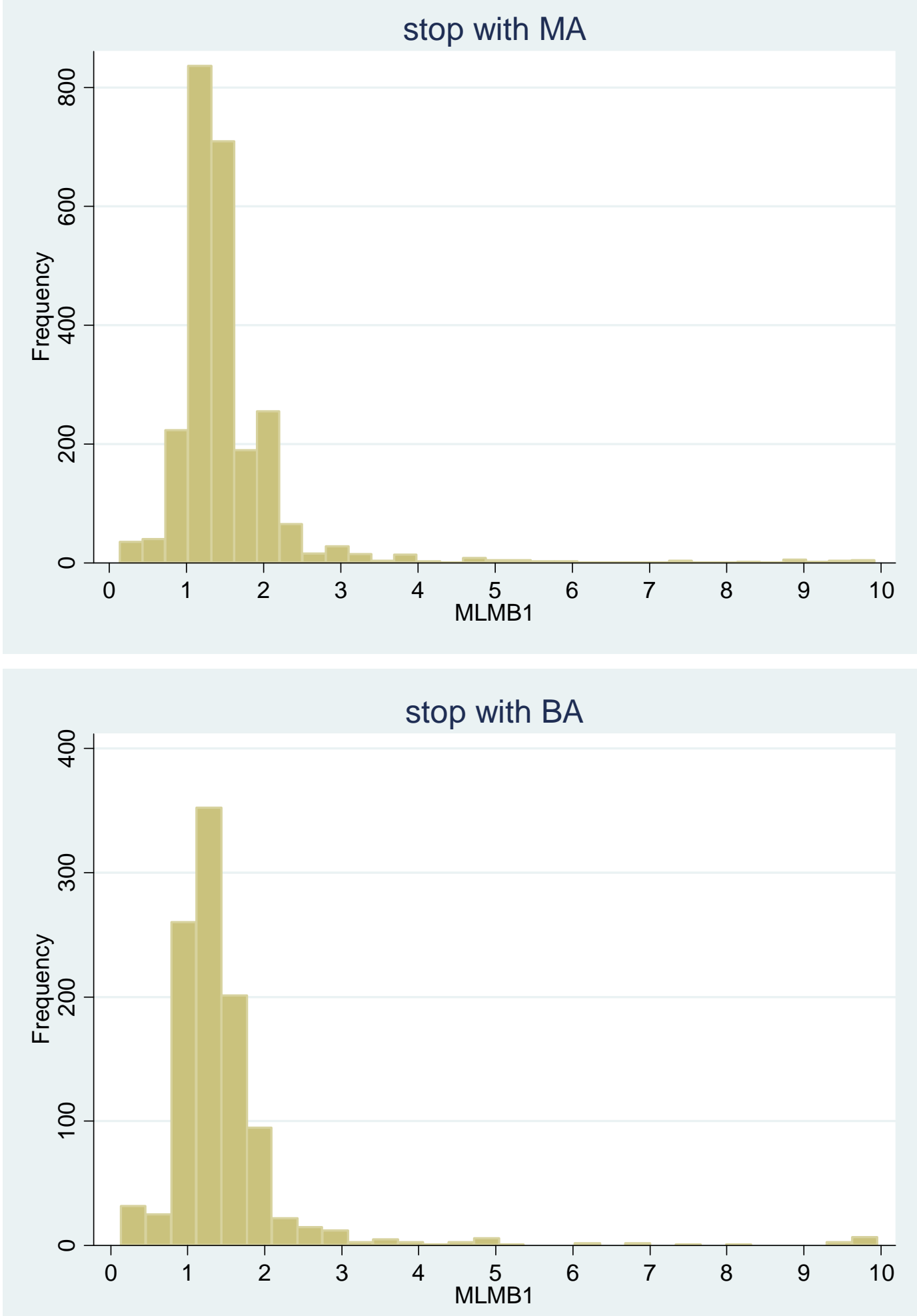
Figure 2. Risk attitude interaction dummies
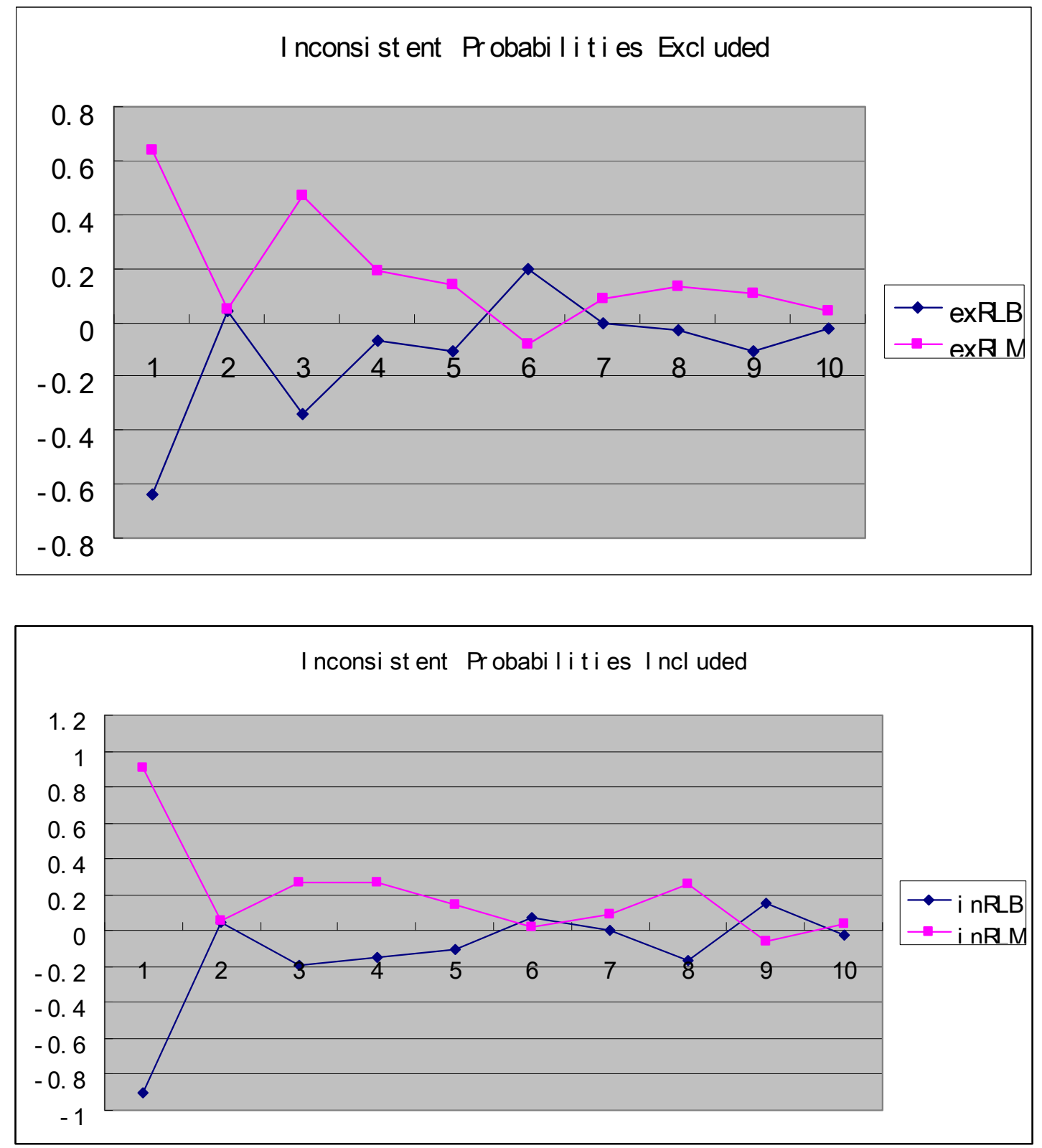
Appendix A. Frequency distribution for risk attitude

How do you see yourself: Are you in general a person who takes risk or do you try to eva de risks? Please grade your choice; 0 = not all; $10=$ very much

\begin{tabular}{|l|l|l|l|}
\hline $\begin{array}{l}\text { Risk } \\
\text { attitude }\end{array}$ & Freq. & Percent & Cum. \\
\hline & & & \\
\hline 0 & 125 & 2.94 & 2.94 \\
\hline 1 & 83 & 1.95 & 4.89 \\
\hline 2 & 197 & 4.63 & 9.53 \\
\hline 3 & 381 & 8.96 & 18.49 \\
\hline 4 & 384 & 9.03 & 27.52 \\
\hline 5 & 709 & 16.68 & 44.20 \\
\hline 6 & 626 & 14.73 & 58.93 \\
\hline 7 & 743 & 17.48 & 76.41 \\
\hline 8 & 536 & 12.61 & 89.01 \\
\hline 9 & 148 & 3.48 & 92.50 \\
\hline 10 & 319 & 7.5 & 100 \\
\hline & & & \\
\hline Total & 4,251 & 100 & \\
\hline
\end{tabular}

